American Journal of Applied Sciences 6 (3): 407-413, 2009

ISSN 1546-9239

(C) 2009 Science Publications

\title{
Time-Dependent Behavior of Piles under Combined Loadings
}

\author{
${ }^{1}$ Mohd Raihan Taha, ${ }^{2}$ Qassun S. Mohammed Shafiqu, ${ }^{1}$ Zamri H. Chik and ${ }^{1}$ Jasim M. Abbas \\ ${ }^{1}$ Department of Civil and Structural Engineering, University Kebangsaan, Malaysia \\ ${ }^{2}$ Department of Civil Engineering, Nahrain University, Iraq
}

\begin{abstract}
This study investigates time-dependent lateral response of piles in elastoplastic soils under combined axial and lateral loadings. Mohr Coulomb model representing the soil and the finite element formulation were described and verified. The transient analysis of pile problem was then carried out and the results of the analysis were presented which demonstrate the effects of the consolidation process on the lateral response of the pile under combined loadings. Lower vertical to horizontal load ratio gives lower differences in deformations with time and becomes more significant with increasing load ratio. Also lateral soil pressure and shear stress in soil increased with time and depth but in a rate lowered as the load ratio decreased.
\end{abstract}

Key words: Pile, consolidation, combined load, lateral response, finite element method

\section{INTRODUCTION}

The stability of foundations and earthworks such as piles in saturated soils is a time-dependent process. This is because any change in total normal stress is initially resisted by pore pressures, which then dissipates over a period of time. The performance of pile foundations subject to axial and lateral load is of considerable importance in geotechnical practice. In view of the complexity involved in analyzing the piles under combined loading, the common practice is to analyze the piles independently for vertical loads to determine their bearing capacity and settlement and for the lateral load to determine their flexural behavior.

It is generally accepted that the finite element method is the major technique used in numerical analysis of geotechnical problems particularly piles and soil consolidation. An efficient formula based on semi-analytical finite element method was developed $^{[15]}$. The formula was described for elastoplastic analysis of consolidation of an axisymmetric soil body subjected to three-dimensional loading and used for consolidation analysis of piles under pure lateral loading.

Several investigations have attempted to study the lateral response of pile under pure lateral load ${ }^{[1,10,17]}$ and with the effect of vertical load in the lateral response of pile $^{[7,8]}$. Anagnostopoulos and Georgiadis ${ }^{[2]}$ attempted to explain this phenomenon through an experimental model supported by two-dimensional (2-D) finiteelement analysis and reported that the modified status of soil stresses and local plastic volume changes in the soil continuum under combined vertical and lateral loads cannot in general be accounted for by the conventional subgrade reaction, elastic half space and other 2-D approaches.

Thus a nonlinear three-dimensional (3-D) finiteelement analysis would be the most appropriate approach. Trochanis et al. ${ }^{[16]}$ attempted to study the axial response of piles with the combination of lateral loads through 3D finite element analysis.

There appear to be no published solutions for combined loaded pile foundations in consolidating elasto-plastic soil. In view of this, the present study focuses on the study of time-dependent behavior of piles subjected to combined vertical and lateral loads through 2-D finite-element analyses. The details of the numerical models, the finite element formulation and results from parametric studies are discussed in the study.

\section{MATERIALS AND METHODS}

Linear elastic model of pile (perfect-plasticity): This model represents Hooke's law of isotropic linear elasticity used for modeling the stress-strain relationship of the pile material. The model involves two elastic stiffness parameters, namely Young's modulus, E and Poisson's ratio, $v$, as shown in Fig. 1. It is primarily used for modeling of stiff structural member for example piles in the soil ${ }^{[4]}$.

Hooke's law can be given by the Eq. 1:

Corresponding Author: Qassun S. Mohammed Shafiqu, Department of Civil Engineering, Nahrain University, Iraq 
Am. J. Applied Sci., 6 (3): 407-413, 2009

$$
\left[\begin{array}{c}
\sigma_{x x}^{\prime} \\
\sigma_{y y}^{\prime} \\
\sigma_{z z}^{\prime} \\
\sigma_{x y}^{\prime} \\
\sigma_{y z}^{\prime} \\
\sigma_{z x}^{\prime}
\end{array}\right]=\frac{E^{\prime}}{\left(1-2 v^{\prime}\right)\left(1+v^{\prime}\right)}\left[\begin{array}{cccccc}
1-v^{\prime} & v^{\prime} & v^{\prime} & 0 & 0 & 0 \\
v^{\prime} & 1-v^{\prime} & v^{\prime} & 0 & 0 & 0 \\
v^{\prime} & v^{\prime} & 1-v^{\prime} & 0 & 0 & 0 \\
0 & 0 & 0 & \frac{1}{2}-v^{\prime} & 0 & 0 \\
0 & 0 & 0 & 0 & \frac{1}{2}-v^{\prime} & \frac{1}{2}-v^{\prime}
\end{array}\right]\left[\begin{array}{c}
\varepsilon_{x x} \\
\varepsilon_{y y} \\
\varepsilon_{z z} \\
\gamma_{x y} \\
\gamma_{y z} \\
\gamma_{z x}
\end{array}\right]
$$

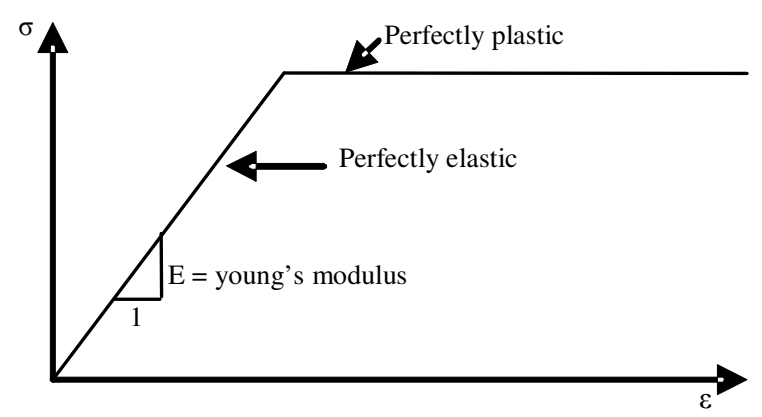

Fig. 1: Stress-strain curve ${ }^{[6]}$

The relationship between Young's modulus, E and other stiffness moduli, such as the shear modulus G, the bulk modulus, $\mathrm{K}$, are given by:

$$
\begin{array}{r}
G=\frac{E}{2(1+v)} \\
K=\frac{E}{3(1-2 v)} \\
E=\frac{(1-v) E}{(1-2 v)(1+v)}
\end{array}
$$

Mohr-coulomb soil model: This elasto-plastic model is based on soil parameters that are known in most practical situations. The Mohr-Coulomb model is used to compute realistic bearing capacities and collapse loads of footings, as well as other applications in which the failure behavior of the soil plays a dominant role. The model involves two main parameters, namely the cohesion intercept, $\mathrm{c}$ and the friction angle, $\phi$. In addition three parameters namely Young's modulus, E, Poisson's ratio, $v$ and the dilatancy angle, $\Psi$ are needed to calculate the complete $\sigma-\varepsilon$ behavior. Mohr Coulomb's failure surface criterion is shown in Fig. 2. The failure envelope only depend on the principal stresses $(\sigma 1, \sigma 3)$ and is independent of the intermediate principle stress $(\sigma 2)^{[6]}$. When mapped in threedimensional stress space, Mohr-Coulomb criteria resolved into an irregular hexagonal pyramid. This

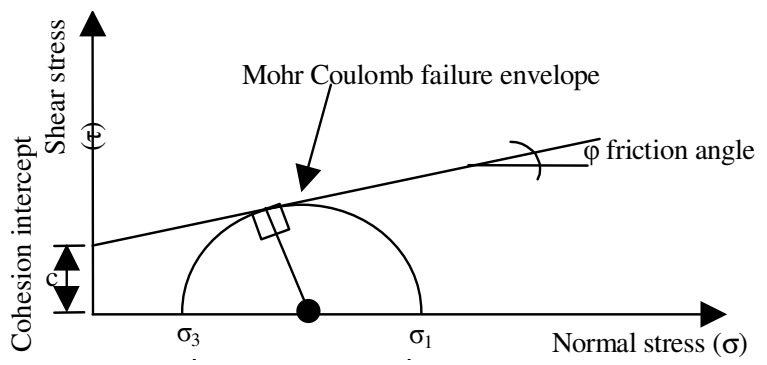

Fig. 2: Mohr Coulomb's failure surface ${ }^{[6]}$

pyramid forms the failure/yield envelope, which is turn governs how soil will behave. The material behaves elastically if the stress point lies within the failure envelope. However, if the stress reaches the yield surface the material will undergo a degree of the plastic deformation. In the Mohr-Coulomb model used herein, it is assumed that the soil has a linear elastic relation until failure.

The usual definition of the equation of MohrCoulomb surface is ${ }^{[13]}$ :

$$
\mathrm{F}=\frac{\sigma_{1}^{\prime}+\sigma_{3}^{\prime}}{2} \sin \phi^{\prime}-\frac{\sigma_{1}^{\prime}-\sigma_{3}^{\prime}}{2}-c^{\prime} \cos \phi^{\prime}
$$

Which, when rewrite in terms of invariants and Lode angle $\theta$ becomes:

$$
F=\frac{1}{3} I_{1} \sin \phi^{\prime}+\sqrt{J_{2}}\left(\cos \theta-\frac{\sin \theta \sin \phi^{\prime}}{\sqrt{3}}\right)-c^{\prime} \cos \phi^{\prime}
$$

where

$$
I_{1}=\sigma_{x}^{\prime}+\sigma_{y}^{\prime}+\sigma_{z}^{\prime}
$$

and

$$
\begin{aligned}
\mathrm{J}_{2}= & \frac{1}{6}\left\{\left(\sigma_{\mathrm{x}}^{\prime}-\sigma_{\mathrm{y}}^{\prime}\right)^{2}+\left(\sigma_{\mathrm{y}}^{\prime}-\sigma_{\mathrm{z}}^{\prime}\right)^{2}+\left(\sigma_{\mathrm{z}}^{\prime}-\sigma_{\mathrm{x}}^{\prime}\right)^{2}\right\} \\
& +\tau_{\mathrm{xy}}^{2}+\tau_{\mathrm{yz}}^{2}+\tau_{\mathrm{zx}}^{2}
\end{aligned}
$$

Finite element formulation: The models described above is incorporated in a finite element program, 
which has the feature of modeling two-dimensional (plane strain and axisymmetric) geotechnical problems such as consolidation written by FORTRAN90 language. This program is primarily based on the programs presented by Smith and Griffiths ${ }^{[14]}$ for the analysis of one and two-dimensional solid by finite element method which is modified for the purpose of this study. So in addition to the Mohr-Coulomb model, the program allows one to assign linear elastic behavior to any part of the problem geometry. Description of all of the program features is beyond the scope of this study and a brief summary of the consolidation theory relevant to this study is given below.

Transient formulation: An incremental formulation was used in the current work producing the matrix version of the Biot equation at the element level presented below ${ }^{[9]}$ :

$$
\begin{aligned}
& {\left[\begin{array}{cc}
\mathrm{K} & \mathrm{L} \\
\mathrm{L}^{\mathrm{T}} & \mathrm{S}+\bar{\alpha} \mathrm{H} \Delta \mathrm{t}_{\mathrm{k}}
\end{array}\right]\left\{\begin{array}{l}
\overline{\mathrm{u}} \\
\overline{\mathrm{p}}\}
\end{array}\right.} \\
& =\left[\begin{array}{cc}
\mathrm{K} & \mathrm{L} \\
\mathrm{L}^{\mathrm{T}} & \mathrm{S}-(1-\bar{\alpha}) \mathrm{H} \Delta \mathrm{t}_{\mathrm{k}}
\end{array}\right]\left\{\begin{array}{l}
\overline{\mathrm{u}} \\
\overline{\mathrm{p}}
\end{array}\right\}+\left\{\begin{array}{c}
\mathrm{dF} / \mathrm{dt}+\mathrm{C} \\
\overline{\mathrm{F}}
\end{array}\right\}
\end{aligned}
$$

Where:

$$
\begin{aligned}
\mathrm{K} & =\text { Element solid stiffness matrix } \\
\mathrm{L} & =\text { Element coupling matrix } \\
\mathrm{H} & =\text { Element fluid stiffness matrix } \\
\overline{\mathrm{u}} & =\text { Change in nodal displacements, } \mathrm{p} \text { change in } \\
& \text { nodal excess pore-pressures } \\
\mathrm{S} & =\text { The compressibility matrix } \\
\overline{\mathrm{F}} & =\text { Load vector } \\
\Delta \mathrm{t} & =\text { Calculation time step } \\
\bar{\alpha} & =\text { Time stepping parameter (equal to one in this } \\
& \text { work) } \\
\mathrm{dF} / \mathrm{dt} & =\text { Change in nodal forces }
\end{aligned}
$$

\section{RESULTS AND DISCUSSION}

The time dependent behavior of a vertical pile embedded in a saturated elasto plastic soil and subjected to a lateral load applied at the midline, is examined here. This problem was also studied ${ }^{[5,15]}$ for a consolidating soil with elastic and elastoplastic skeleton, respectively. In the study presented herein, the pile will then be subjected to both vertical and lateral load simultaneously.

A pile with diameter $D_{p}$ is embedded in a layer of saturated cohesionless soil which obeys the MohrCoulomb failure criterion The friction angle of the soil is assumed to be $\phi=30^{\circ}$. The soil is also assumed to

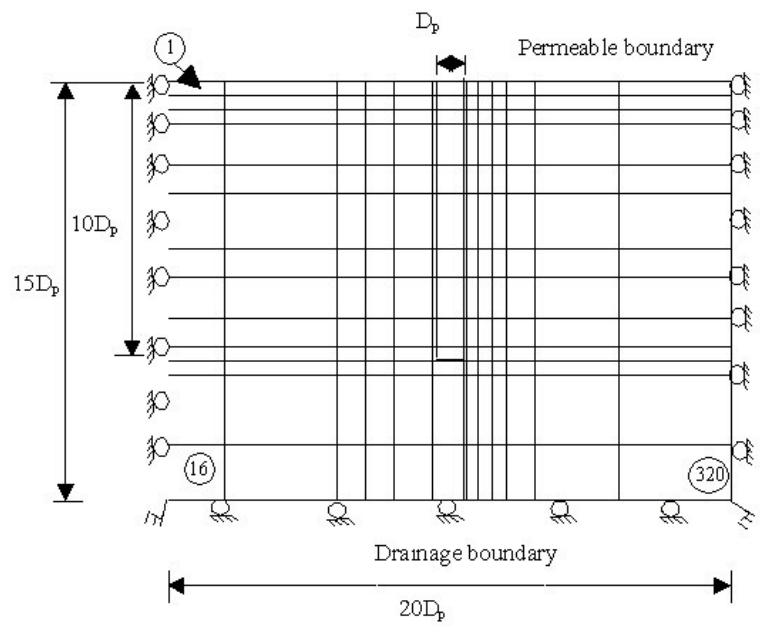

Fig. 3: Finite element mesh

have a submerged unit weight of $\gamma_{\text {sub }}=0.7 \gamma_{\mathrm{w}}$, where $\gamma_{\mathrm{w}}$ is the unit weight of pore water, a Young's modulus for fully drained conditions given by $\mathrm{E}_{\mathrm{s}}^{\prime}=3000 \gamma_{\mathrm{w}}$ and a Poisson's ratio $\mathrm{v}^{\prime}=0.30$. The initial value of the coefficient of lateral earth pressure is $\mathrm{K}_{0}=0.5$. The Young's modulus of the pile material is $\mathrm{E}_{\mathrm{p}}=1000 \mathrm{E}_{\mathrm{s}}$. The problem was analyzed assuming elastic as well as elasto-plastic models for the soil. The finite element mesh and dimensions of the problem are shown in Fig. 3. All elasto-plastic analyses have been carried out using 8-node quadrilateral finite elements.

In order to examine the time dependent consolidation behaviour of the pile, it is convenient to introduce a non-dimensional time factor $\mathrm{T}$, defined as $^{[15]}$ :

$$
\mathrm{T}=\frac{\mathrm{k}\left(1-v_{\mathrm{s}}^{\prime}\right) \mathrm{E}_{\mathrm{s}}^{\prime} \mathrm{t}}{\gamma_{\mathrm{w}}\left(1-2 v_{\mathrm{s}}^{\prime}\right)\left(1+v_{\mathrm{s}}^{\prime}\right) \mathrm{D}_{\mathrm{p}}^{2}}
$$

where $\mathrm{k}$ is the coefficient of soil permeability and $\mathrm{t}$ represents time.

In the elastoplastic analysis, a horizontal load, $\mathrm{H}$, varied from $\mathrm{H}=5 \gamma_{\mathrm{w}} \times \mathrm{D}_{\mathrm{p}}^{3}$ to $\mathrm{H}=15 \gamma_{\mathrm{w}} \times \mathrm{D}_{\mathrm{p}}^{3}$ are applied to the pile head during a total time of $\mathrm{T}=0.0001$. This loading was maintained constant with time and the analyses were continued, allowing excess pore pressures to dissipate and thus for the soil to consolidate.

The time-dependent lateral displacements of the pile head predicted by the elastoplastic analyses are ploted in Fig. 4, for the case where the horizontal load is $\mathrm{H}=5,15,25$ and $50\left(15 \gamma_{\mathrm{w}} \times \mathrm{D}_{\mathrm{p}}^{3}\right)$, respectively. Higher displacements were observed with time due to consolidation process and as it can be noticed the 
Am. J. Applied Sci., 6 (3): 407-413, 2009

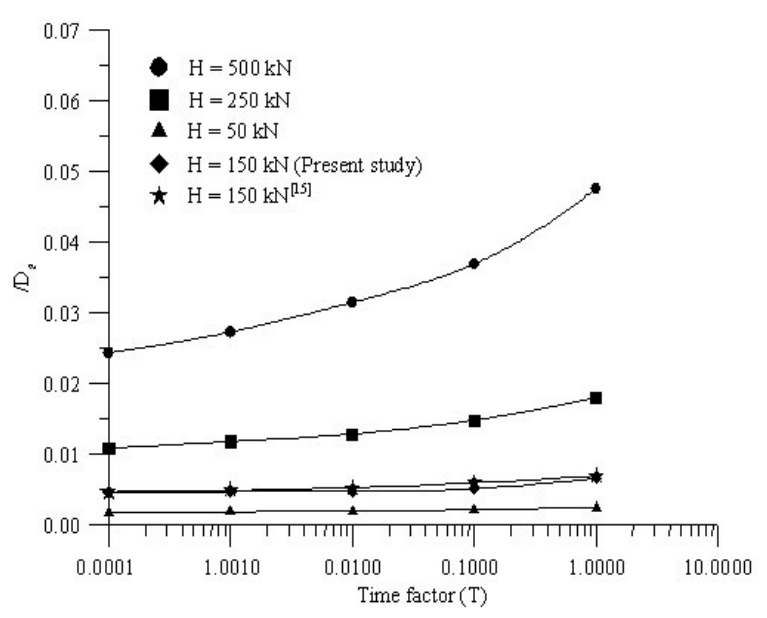

Fig. 4: Comparison of the lateral displacements of the pile head in elastoplastic soils

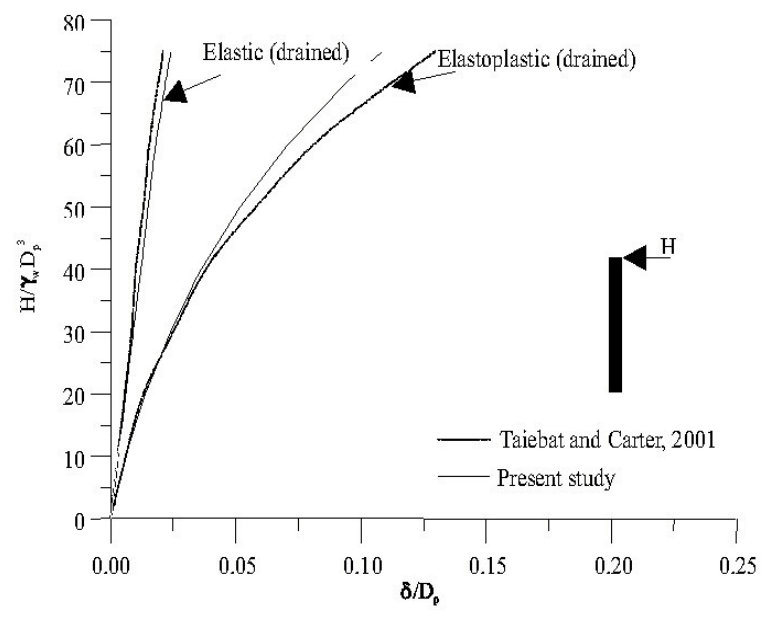

Fig. 5: Comparison of the pile response with different soil models, each deforming under fully drained conditions

higher the applied lateral load the higher the percentage of increasing in displacements with time occurred. Good comparison between the present study and Taiebat and Carter ${ }^{[15]}$ results was predicted.

The predicted load-displacement curves for the pile head, for cases where the pile deforms under fully drained state and rapid loading (i.e., undrained) conditions, are presented in Fig. 5 and 6. Cases are plotted for the elastoplastic soil model as well as for the elastic soil model. A significant dependence of the response of the pile on the assumed soil model can be observed in the drained case where the displacement of the pile head predicted using the Mohr Coulomb model is about four times that predicted using elastic model.

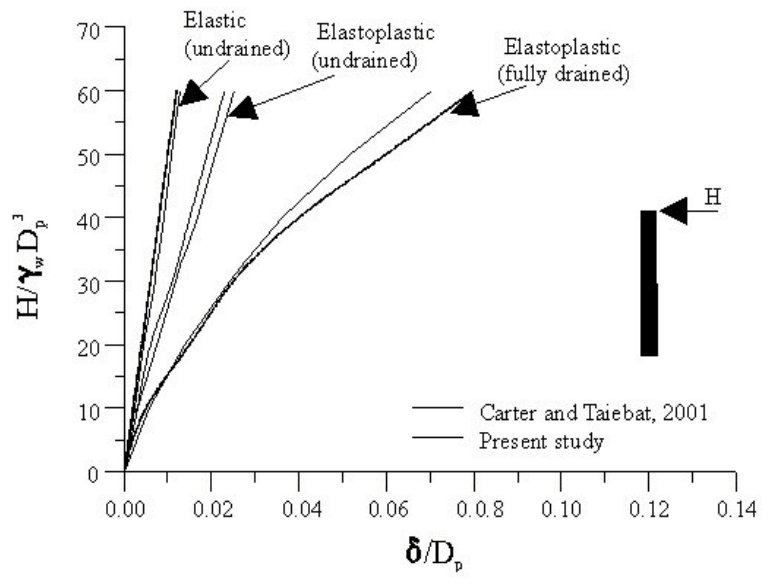

Fig. 6: Lateral displacement relationships for laterally loaded piles under drained and undrained conditions

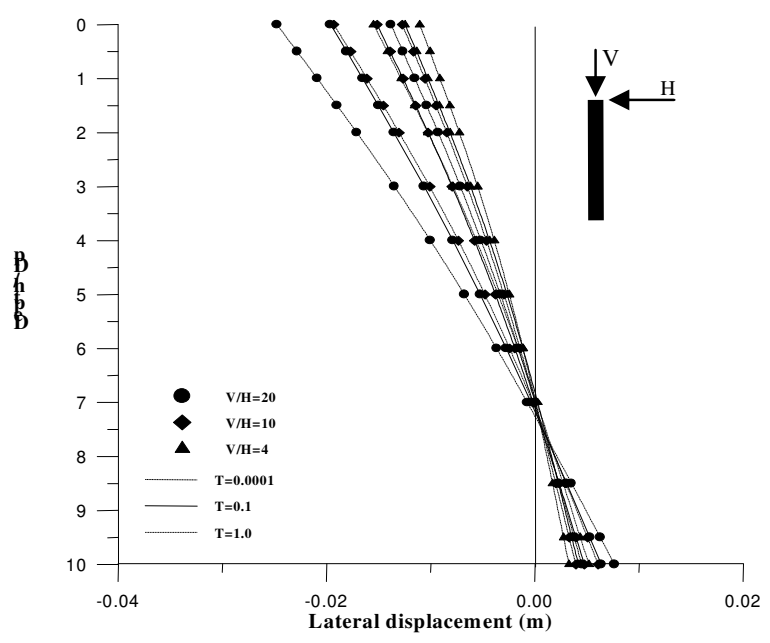

Fig. 7: Lateral displacement of pile with depth under combined loads

While the response of the pile during rapid loading is almost linear and close to the elastic response with head displacement about twice that of elastic analysis. Again good agreement was observed between present study and Taiebat and Carter ${ }^{[15]}$ results.

The responses of the pile in elastoplastic soil subjected to both lateral and axial load simultaneously and deforming under rapid loading conditions followed by consolidation are taken. The lateral load was taken as $\mathrm{H}=25\left(15 \gamma_{\mathrm{w}} \times \mathrm{D}_{\mathrm{p}}^{3}\right)$ and the vertical load varied from $\mathrm{V} / \mathrm{H}=4,10$ and 20 , as the lateral loads are in the order of $10-15 \%$ of the vertical loads ${ }^{[11,12]}$. Fig. 7 show the 


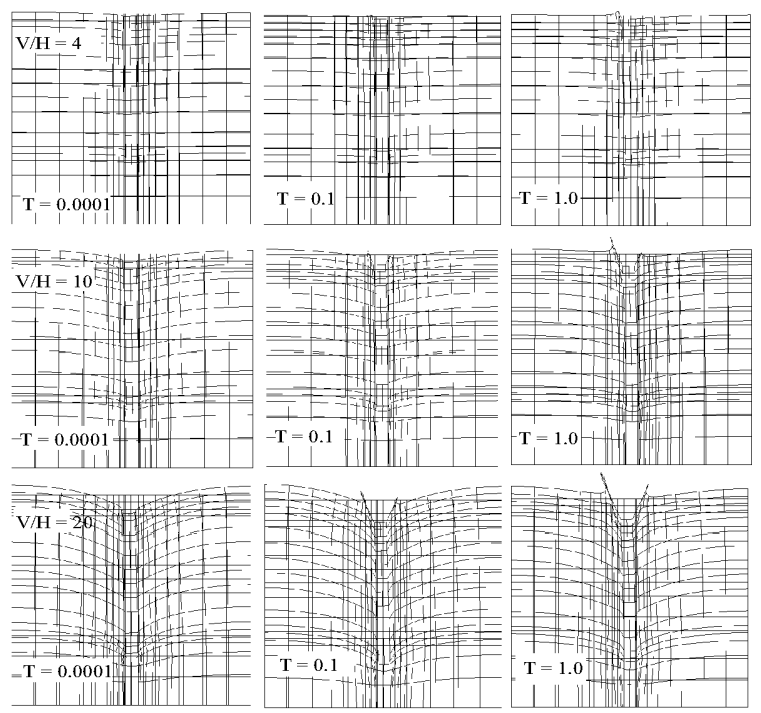

Fig. 8: Deformed mesh for the two-dimensional pile problem following the time factors of $\mathrm{T}=0.0001, \quad 0.1$ and 1.0 (Deformation exaggerated by a factor of 5)

lateral deformation of the pile with increasing the axial load and time and as it can be noticed that lower vertical load gives smaller differences in deformations with time. The difference became more significant with increasing load ratio $(\mathrm{V} / \mathrm{H})$. Figure 7 also show that lateral displacements of the pile at time factor $\mathrm{T}=1.0$ under load ratios $(\mathrm{V} / \mathrm{H}=4$ and 10$)$ are close to that for time factor $\mathrm{T}=0.1$ under load ratios $(\mathrm{V} / \mathrm{H}=10$ and 20$)$, respectively. This gives an indication that under a certain load ratio increasing the time factor about 10 times gives lateral displacements which are almost close to that from the twice certain load ratio at the earlier time factor. While at lower time factor (i.e., $\mathrm{T}=0.0001$ ) insignificant increasing in displacements with time is observed. The differences in displacements with time factor and load ratios are shown clearly in Fig. 8, which draws the displacements exaggerated by a factor of 5 and plotted with the original finite element mesh.

The Lateral soil pressures $p$ and shear stresses $C$ in soil resulting from the combined loads are shown in Fig. 9 and 10. It can be seen that the pressure and shear increased with time and depth but in a rate lowered as the load ratio decreased. Also higher values of pressures and shear stresses near the ground surface were predicted, this may be attributed to the boundary effects and as the point of measurement is close to the tip of the pile where the vertical and lateral load applied.

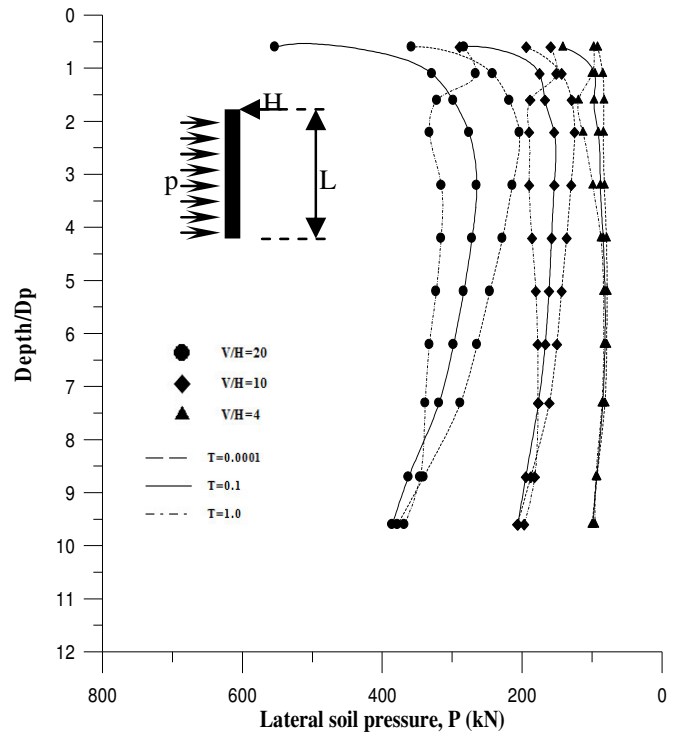

Fig. 9: Lateral pressure of soil with depth under different load ratio and time factor

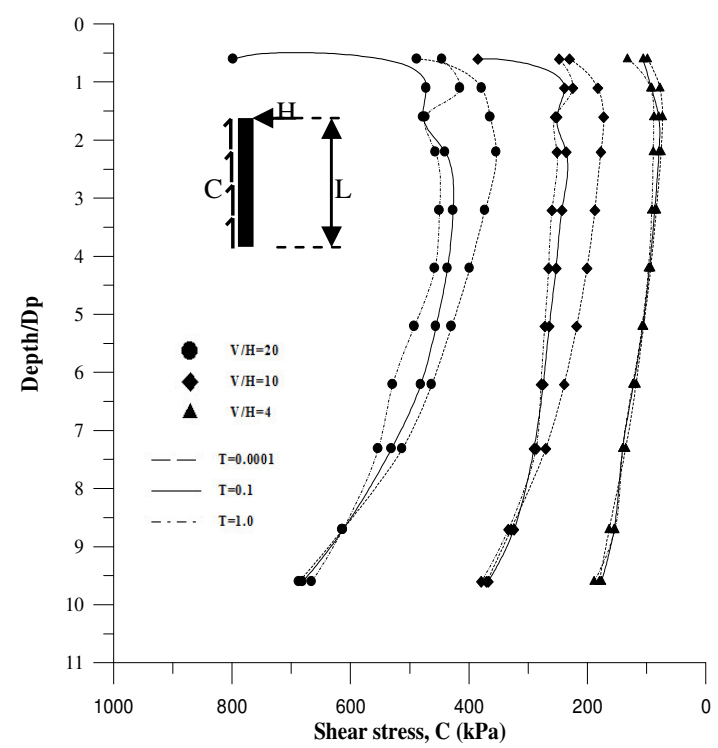

Fig. 10: Shear stress of soil with depth under different load ratio and time factor

Figure 11 and 12 show time wise variation of vertical and lateral displacements of the pile tip, respectively. During the early stage of consolidation and at lower load ratios insignificant increase in lateral displacements were predicted and becoming more noticeable at higher time factors. The increaes in displacements appeared more obvious with time from 


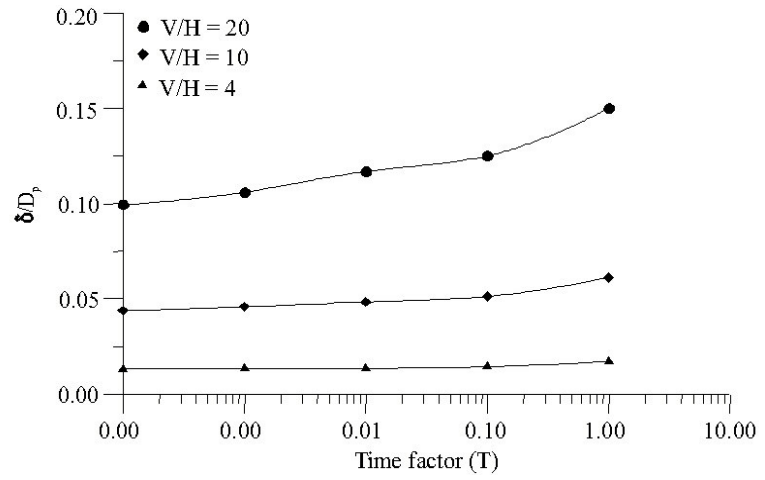

Fig. 11: Pile head axial displacement vs. time for the elastoplastic analysis

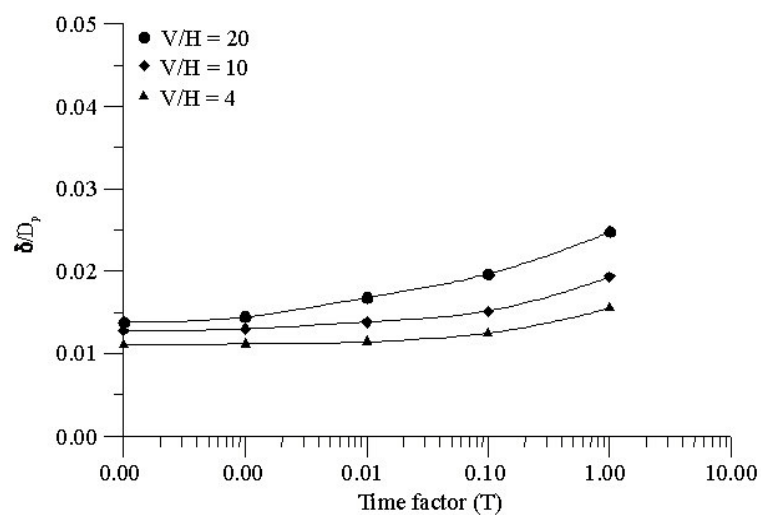

Fig. 12: Pile head lateral displacement vs. time for the elastoplastic analysis

the early stages of consolidation at higher load ratio. Also the difference between the vertical and horizontal displacements of the tip of the pile is small at the lower load ratio (i.e., $\mathrm{V} / \mathrm{H}=4$ ) becoming larger with increasing the load ratio and time.

\section{CONCLUSIONS}

A fully transient program for the analysis of pile problems in saturated soil is develop. This was to allow the transition between the states of drained and undrained behavior to be investigated. An algorithm for carrying out such an analysis has been presented. The transient response of the saturated porous media was based on the theory of consolidation ${ }^{[3]}$. Also it should be emphasized that the results presented herein were based on elastic and elastoplastic soil models. The results of the elastoplastic analyses of pile problem in saturated soil under lateral and combined loadings are presented. The following conclusions were observed:
- A significant dependence of the response of the pile on the assumed soil model can be observed in the drained case. The displacement of the pile head predicting using Mohr Coulomb model is about four times that predicted using elastic model, while the response of the pile during rapid loading is almost linear and close to the elastic response of the pile with head displacement about twice that of elastic analysis

- Higher displacements were observed with time due to consolidation process and the higher the lateral load applied, the greater the percentage of increasing in displacements with time occurred

- For pile under combined loadings, lower vertical load gives smaller differences in deformations with time and became more significant with increasing loads

- Lateral soil pressure and shear stress in soil increased with time and depth but the increase with time is smaller as the load ratio decreased

- Time wise variation of vertical and lateral displacement of the pile tip shows that at the early stage of consolidation and at lower load ratios insignificant increase in displacements were observed but became more noticeable at higher time factors. At higher load ratio the increase in displacements appeared more clearly with time from the early stages of consolidation.

- The difference between the vertical and horizontal displacements of the pile head is small at the lower load ratio and became enlarged with increasing the load ratio and time

\section{REFERENCES}

1. Abbas, J.M., Z.H. Chik and M.R. Taha, 2008. Single pile simulation and analysis subjected to lateral load. Elect. J. Geotech. Eng., 13: 1-15. http://www.ejge.com/2008/Ppr0830/Ppr0830.pdf.

2. Anagnostopoulos, C. and M. Georgiadis, 1993. Interaction of axial and lateral pile responses. J. Geotech. Eng. Division, 119: 793-798. Doi: 10.1061/(ASCE)0733-9410(1993)119:4(793).

3. Biot, M.A., 1941. General theory of threedimensional consolidation. J. Applied Phys., 12: 155-164. http://www.pmi.ou.edu/Biot2005/ papers/FILES/040.PDF.

4. Brinkgreve, R.B.J. and W. Broere, 2004. Plaxis 3D Foundation-Version1.5, Netherlands. http://www.terrasol.com/Softwares/Plaxis/General_Infor mation_3DFoundationv15.pdf. ISBN-10: 9076016011. 
5. Carter, J.P. and J.R. Booker, 1983. Consolidation of axi-symmetric bodies subjected to non-axisymmetric loading. Int. J. Numer. Anal. Methods Geomech., 7: 273-281. Doi: 10.1002/nag.1610070210.

6. Johnson, K., P. Lemcke, W. Karunasena and N. Sivakugan, 2006. Modelling the loaddeformation response of deep foundation under oblique load. Environ. Modell. Software, 21 (9): 1375-1380. Doi: 10.1016/j. envsoft.2005.04.015.

7. Karthigeyan, S., V.V.G.S.T. Ramakrishna and K. Rajagopal, 2006 . Influence of vertical load on the lateral response of piles in sand. Comput. Geotech., 33: 121-131. Doi: 10.1016/j.compgeo.2005.12.002.

8. Karthigeyan, S., V.V.G.S.T. Ramakrishna and K. Rajagopal, 2007. Numerical investigation of the effect of vertical load on the lateral response of piles. J. Geotech. Geoenviron. Eng., 133: 512-521. Doi: 10.1061/(ASCE)1090-0241(2007)133:5(512).

9. Lewis, R.W. and B.A. Schrefler, 1987. The finite element method in the deformation and consolidation of porous media. John Wiley and Sons Inc.,New York, NY. ISBN: 9780471912101

10. Muqtadir, A. and C.S. Desai, 1986. Threedimensional analysis of a pile-group foundation. Int. J. Numer. Anal. Methods Geomech., 10: 41-58. Doi: $10.1002 /$ nag. 1610100104.
11. Poulos, H.G. and E.H. Davis, 1980. Pile Foundation Analysis and Design. 2nd Ed. John Wiley and Sons, Inc, United States. ISBN: 0471020842 : 9780471020844.

12. Rao, S.N., V.G. Ramakrishna and M.B. Rao, 1998 Influence of rigidity on laterally loaded pile groups in marine clay. J. Geotech. Geoenviron. Eng., 124: 842-549. Doi: 10.1061/(ASCE)10900241(1998)124:6(542).

13. Smith, I.M. and D.V. Griffith, 1982. Programming the Finite Element Method. 2nd Ed. John Wiley and Sons, Chisester, UK.

14. Smith, I.M. and D.V. Griffiths, 1998. Programming Finite Element Method. 3rd Ed. John Wiley and Sons, Chisester, UK.

15. Taiebat, H.T. and J.P. Carter, 2001. A semianalytical finite element method for threedimensional consolidation analysis. Comput. Geotech., 28: 55-78. Doi: 10.1016/S0266352X(00)00019-7.

16. Trochanis, A.M., J. Bielak and P. Christiano, 1991. Three dimensional nonlinear study of piles. J. Geotech. Eng., 117: 429-447. Doi: 10.1061/(ASCE)0733-9410(1991)117:3(429).

17. Yang, Z. and B. Jeremic, 2005. Study of soil layering effects on lateral loading behaviour of piles. J. Geotech. Geoenviron. Eng., 131: 762-770. Doi: 10.1061/(ASCE)1090-0241(2005)131:6(762). 